\title{
Mental Health Literacy of Pharmacy Students Compared to Nursing and Medical Students
}

Radhika Devraj, PhD ; Gireesh V. Gupchup, PhD'; David Henson, PharmD ${ }^{2}$

${ }^{1}$ Southern Illinois University Edwardsville School of Pharmacy; ${ }^{2}$ Walgreens, Springfield, IL

\begin{abstract}
Objectives: To determine and compare the mental health literacy of pharmacy, nursing, and medical students.

Methods: Pharmacy, nursing, and medical students in the final year of their didactic program were administered a widely used mental health literacy questionnaire either via paper (nursing) or via email (pharmacy and medicine). For email questionnaires, weekly reminder emails with links for survey completion were sent over a three-week period. The questionnaire consisted of a vignette describing either depression or schizophrenia followed by items about helpfulness of a variety of interventions, medications, and activities. Depression and schizophrenia versions of the questionnaire were randomly administered to respondents in the three programs such that respondents received either male (John) or female (Jane) versions of the vignettes.

Results: A total of 161 out of 253 potential students responded to the survey (63.6\% response rate). Majority of the respondents were female (75\%), white (84.6\%), had currently or in the past year interacted with people diagnosed with mental disorders (90\%), and had multiple opportunities for exposure to mental health content in their coursework (49\%). While a majority of respondents in all three programs correctly identified the vignettes as either depression (87\%) or schizophrenia (73\%), depression was identified correctly by a greater percent of those in pharmacy (88.5\%) and nursing (88.4\%), and schizophrenia was identified by a greater percent in medicine (82\%). However, there were no significant differences by program type for correct identification of vignette. Helpfulness of various interventions, medications, and activities did not differ significantly for the depression vignette. Two significant differences by program type were noted for the schizophrenia vignette. A larger percent (72\%) of nursing students perceived antidepressants as helpful for schizophrenia as compared to pharmacy (55\%) and medical (18\%) students. Students from all three programs responded similarly to the question on likely prognosis for those with depression/schizophrenia, both with and without professional help (p>0.01).

Conclusions: Majority of students in each discipline were able to correctly identify patients with depression or schizophrenia and have similar levels of mental health literacy. The profile of responses suggest that pharmacy and nursing students were more clear about helpfulness of interventions for depression, than for schizophrenia. Given the extent of the problem of mental health, additional and continuously reinforced training on mental health throughout the four-year curriculum is necessary for first line providers such as pharmacists, nurses, and physicians.
\end{abstract}

Keywords: mental health literacy, knowledge, health professional students

\section{Introduction}

Mental health disorders (MHDs) cover a wide range of disorders such as anxiety disorders, depression and other mood disorders, eating disorders, personality disorders, and psychotic disorders such as schizophrenia. According to the National Alliance on Mental Illness, 46.6 million people in the U.S. or roughly $20 \%$ of the population, will experience a mental illness in any given year. Mental illnesses have been estimated to cost $\$ 193$ billion every year in lost earnings. ${ }^{1}$ Awareness and understanding of mental health disorders and their management are essential not only for patients and caregivers, but also for providers who may come across such patients. Such understanding is broadly termed as mental health literacy. Mental health literacy has been defined as "the knowledge and beliefs about mental disorders which aid their recognition, management, or prevention. ${ }^{2}$ Thus mental

\section{Corresponding author: Radhika Devraj, PhD}

Southern Illinois University Edwardsville School of Pharmacy

200 University Park Drive, Suite 250

Edwardsville, IL 62026- 2000

Phone: 618-650-5137; Fax: 618-650-5152

Email: rdevraj@siue.edu health literacy is multifactorial consisting of: a) ability to recognize specific disorders, b) knowledge and beliefs about risk factors and causes, c) knowledge and beliefs about selfhelp interventions, d) knowledge and beliefs about professional help available, e) attitudes facilitating recognition and appropriate help-seeking, and f) knowledge of how to seek mental health information. ${ }^{2}$ The high prevalence of mental health disorders necessitates that health care professionals have adequate mental health literacy in order to not only correctly differentiate across the spectrum of mental health disorders, but also be knowledgeable about management and signs of deterioration in mental health of the patients they serve.

On the other hand, there is literature evidence that health care professionals such as pharmacists have negative attitudes towards patients with mental illness, which in turn, influences their willingness to serve such patients. ${ }^{3-5} \quad$ Phoeko et al reported that patients with mental illness received fewer pharmacy services than patients with cardiovascular disorders, ${ }^{3}$ while another study reported that pharmacists were significantly more willing to provide services to patients with asthma than to those with mental illness. ${ }^{4}$ Given this, it is not surprising that addressing mental health stigma has been 
a significant focus area in the literature on mental health, with a large amount of research on stigma being conducted using students. ${ }^{6-15}$

Mental health literacy of health care providers or of student providers has not been examined in the United States. Previous research on mental health literacy is based in Australia and has largely focused on examining the mental health literacy of various Australian populations such as the Australian public, ${ }^{16,17}$ young people, ${ }^{18}$ and health professionals such as physicians, ${ }^{19-21}$ and pharmacists. ${ }^{22}$ Except for one study conducted in Singapore that surveyed nursing and medical students and reported results in aggregate, ${ }^{23}$ existing studies on health professional students are limited to only one profession and mostly conducted outside the United States. ${ }^{24-}$ 26 There has been no report in the literature comparing all three primary disciplines (pharmacy, nursing, and medical students) within the same study that has been conducted in the United States. As future health care professionals, pharmacy, nursing, and medical students' mental health literacy will significantly impact future care delivery of patients with mental health disorders. While mental health topics are taught in the curricula of health professional programs (pharmacy, nursing, and medicine), they are usually taught from a clinical perspective focused on treatment, and may not comprehensively address knowledge, beliefs, attitudes, helpseeking behaviors etc., that is, those mental health literacy concepts that are valuable to patients. For example, in schools of pharmacy, psychiatric topics are covered typically as part of therapeutics-based courses and consist of less than $10 \%$ of course content in the courses within which they are taught. ${ }^{27,28}$ Thus, they may not focus on content related to knowing how to seek mental health information, self-treatments, professional help available, and on attitudes that promote recognition and appropriate help seeking behaviors. ${ }^{16}$ Similarly, medical and nursing school curricula are generally broad and cover numerous body systems focusing primarily on clinical aspects of mental health. Awareness of future health professionals' mental health literacy will enable educators to tailor their teaching to ensure that they develop health care professionals that have not only optimal clinical knowledge about mental health, but also have high mental health literacy necessary to serve the mental health needs of the primary care patient populations that they will encounter in practice.

The purpose of this study was to compare the mental health literacy levels of pharmacy, nursing, and medical students. The specific objectives were:

a) To determine the mental health literacy of medicine, nursing, and pharmacy students who have completed their didactic training on mental health and are in the final year of training.

b) To compare the mental health literacy of medicine, nursing, and pharmacy students.
Methods

Study Participants

Pharmacy $(n=80)$, nursing $(n=120)$, and medical $(n=72)$ students in the final year (year 4) of their professional program at one university formed the study population. The primary eligibility criterion for participation in the study included completion of the didactic portion of the curriculum on topics related to mental health. All Year 4 pharmacy and medical school students were eligible, final year nursing students who completed didactic training on mental health topics in the fall semester $(\mathrm{N}=120)$ were considered eligible to participate in the study. Study recruitment involved a two-step process: a) approaching nursing and medical school administrators for permission to conduct the survey (pharmacy school did not require permission), b) contacting appropriate faculty within the schools to seek approval to administer the survey either via email or in person. Human subjects' approval at the university where the study was conducted was received prior to data collection.

\section{Study instrument}

Mental health literacy was assessed by the widely used mental health literacy questionnaire by Jorm et al. ${ }^{2}$ The validity of this tool has been supported in the literature. ${ }^{29}$ The mental health literacy questionnaire uses a vignette of a person with a mental disorder, either depression or early schizophrenia (Table 1). The vignettes were created to meet the diagnostic criteria for either major depression or early schizophrenia according to DSM -IV an ICD-10. ${ }^{17}$ The vignettes were randomly assigned to respondents such that respondents received either male (John) or female (Jane) versions of either depression or schizophrenia vignette. Based on the vignette, participants were asked what if anything, was wrong with the person described in the vignette. This was followed by a series of questions regarding the likely helpfulness of a variety of interventions, and the likely prognosis of the vignette with and without professional help. Demographic data of survey participants that were collected included age, gender, race, and prior personal experience working with patients with mental health disorders and curriculum-based questions such as year in the program, and prior coursework on mental health. Finally, a single open-ended question for additional comments, if any, was also included.

\section{Procedures}

The data collection format varied among the three schools depending on feasibility and optimal method to access study participants. Flexibility in survey format was essential because fourth year pharmacy and medical students were away from campus due to clinical rotations during the survey administration time and hence could not be easily approached for face-to face survey administration. All surveys included a unique identifier that was used solely for tracking purposes. Completion of the survey was considered as consent to participate in the study. 
School of Nursing. Eligible fourth year nursing students were approached in the classroom, and a brief description of the study, identical to that provided for the Schools of Medicine and Pharmacy (see below) was provided along with an invitation to participate in the study. Participants were requested to complete a paper version of the survey in the classroom. Completion of the survey took less than 15 minutes and was carried out on one occasion at the end of one of their nursing classes.

Schools of Medicine and Pharmacy: An electronic version of the survey was designed using Qualtrics (Qualtrics, Provo, UT). One day prior to beginning of the data collection period, an email was sent to fourth year pharmacy and medical students informing them about the upcoming survey and requesting them to check their emails the following day for the survey link. On the first day of the data collection period, an email with a Qualtrics survey link was sent. Weekly reminder emails along with the Qualtrics survey links were also sent. Surveys remained active for three weeks. Additionally, for the School of Pharmacy, in order to boost response rates, a Facebook reminder request to check their emails for the Qualtrics survey was made to the Year 4 Facebook group.

\section{Statistical Analysis}

Data were analyzed using SPSS (IBM Corp. Released 2017. IBM SPSS Statistics for Windows, Version 25.0. Armonk, NY: IBM Corp). Frequencies were used to analyze categorical data. Chi-square tests were used to assess differences in professions with respect to helpfulness of various interventions. For cells with expected frequencies less than 5, Fisher's exact tests were performed. Due to the large number of statistical tests, a conservative $p<0.01$ was used as the significance level.

\section{Results}

A total of 161 students out of 253 potential students responded to the survey from all three schools $(63.6 \%$ response rate). Individual school response rates were $60.5 \%$ (46 out of 76 students) for Pharmacy, 29\% (20 out of 69 students) for Medicine and $79.6 \%$ (86 out of 108 students) for Nursing. Table 2 shows the demographics of the sample. None of the students indicated that they had no coursework or experiential training in mental health. Significant differences by program type $(p<0.01)$ were present for the following demographics: age, gender, whether they interacted with patients with mental health disorders regularly, and coursework completed. While there were significant differences by program type based on coursework completed, it is unclear if these differences arose because of measurement error in the question leading to students checking all the options that applied to them.

\section{Correct identification of vignette}

The first question in the questionnaire referred to whether respondents could correctly identify the disease state based on the description provided in the vignette shown in Table 1.
Twenty nine open-ended responses were received for the question, "From the information given, what if anything, is wrong with Jane/John based on the vignette." Ten respondents did not answer the question, hence the total number of respondents for this question was 151 . The aforementioned responses were first combined into five categories which included Schizophrenia $(n=58)$, depression $(n=74)$, hallucinations $(n=7)$ (included categories hallucinations with paranoia, and delusions with hallucinations), multiple disorders reported $(n=6$; included personality or mental disorder, general psychological disorder, isolation, agoraphobia, paranoia, and not doing activities of daily living), and Other ( $n=15$; fatigue, sleeping too much, stressed out, thyroid, feeling sad, nothing wrong, not enough information, psychological disorder, paranoid). For ease of display, the five categories were further reclassified into the following three categories: schizophrenia $(n=58)$, depression $(n=74)$, and other $(n=28)$. The percentage of respondents correctly identifying the type of disorder by school is shown in Figure 1. There were no significant differences by program type in students' ability to identify depression or schizophrenia vignettes correctly.

\section{Helpfulness of interventions}

Table 3 provides percent ratings of perceived helpfulness of various interventions such as different people, medications, and activities for depression and schizophrenia. Assuming a cutoff of $66 \%$ helpfulness as recommended in the literature, ${ }^{28}$ medical providers such as psychiatrists (range $88.5-100 \%$ ), psychologists (range 85-89\%), and family physicians (range 73$100 \%$ ), and counselors (range 88.5-97.6\%) were the highest rated providers for their helpfulness by all three health professions for depression. There were non-significant differences among the three program types for their perceptions of helpfulness of remaining types of individuals included in the survey. Nursing students included several additional categories such as telephone counseling $(76 \%$, $\mathrm{N}=32)$, and help from close family $(79 \%, \mathrm{~N}=33)$, and close friends $(79 \%, N=33)$, while medical students included only social worker $(78 \%, N=7)$ and help from close family $(67 \%$, $\mathrm{N}=6$ ). Pharmacy students did not have any additional suggestions. For schizophrenia, psychiatrist (82-97.6\%), psychologist (82-90.5\%), and counselor (75-91\%) were considered helpful by all three program types. Nursing and medical students also added family physician (67-73\%), while medical and pharmacy students also considered social workers $(75-82 \%)$ to be helpful. None of the differences by program type were significant. The least helpful rating for both depression and schizophrenia was when the individual tries to deal with the problem on his/her own (2.4-22\% for depression and $0 \%$ for schizophrenia), or using a naturopath or herbalist (11.5-33\% for depression, and $2.4 \%-18.2 \%$ for schizophrenia). A much lower percent of respondents perceived pharmacists as being helpful across all three disciplines for both depression (33.3-46.2\%) and schizophrenia (18.2-35\%). No significant differences by discipline were present for both depression and 
schizophrenia for student perceptions of individuals that were helpful.

All three disciplines considered antidepressants as most helpful for treating depression (78-86\%), while they perceived antipsychotics to be most helpful for treating schizophrenia (75-91\%). Additionally, more than $70 \%(\mathrm{~N}=31)$ of nursing students also perceived antidepressants as being helpful for schizophrenia. Nursing students were the only discipline that had some respondents considering other medications such as vitamins $(30 \%, \mathrm{~N}=13)$, analgesics $(2.4 \%, \mathrm{~N}=1)$, sedatives $(12 \%$, $\mathrm{N}=5)$, and tranquilizers $(11.6 \%, \mathrm{~N}=5)$ to be helpful for depression. Specifically, there were significant differences by program type for the schizophrenia vignette regarding the use of antidepressants $(p<0.01)$. A large percent $(72 \%, N=31)$ of nursing students viewed the use of antidepressants for schizophrenia as being helpful compared to 55\% ( $N=11)$ of pharmacy students and $18 \%(\mathrm{~N}=2)$ of medical students. No other significant differences by discipline were present.

Participants were also asked about helpfulness of various activities for both depression and schizophrenia. Performing physical activity (88.4-100\%), reading about others with similar problems (84-89\%), relaxation courses (78-95\%), psychotherapy (65-77\%), cognitive behavior therapy (65$100 \%$ ) and receiving information about health problem from a health educator (77-88\%) were rated by the three disciplines as the highest perceived activity types for managing depression. Additionally, nursing (84\%, $\mathrm{N}=36$ ) and medical (78\%, N=7) students perceived "getting out more" as being helpful for depression. Nursing $(67 \%, \mathrm{~N}=29)$ and pharmacy (69\%, $N=18)$ students felt that "cutting alcohol altogether" would be helpful as well. Use of hypnosis $(18.6 \%, N=8)$, and admission to a psychiatric ward $(11.6 \%, \mathrm{~N}=5)$ were chosen as helpful activities for depression only by small percent of nursing students, but not by pharmacy or medical students.

Psychotherapy (85-95\%), cognitive behavior therapy (72-95\%), and reading about people with similar problems and how they dealt with it (74-91\%), and receiving information about health problem from a health educator (80-91\%), and becoming more physically active (65-75\%) were perceived by all three disciplines as being helpful activities for schizophrenia. Completely cutting out alcohol altogether was also considered helpful by nursing $(84 \%, N=36)$ and medical $(82 \%, N=9$ ) students. At the same time, among the activities for schizophrenia, only one activity "having an occasional alcoholic drink to relax" was significantly different by discipline $(p<0.01)$. The small number of responses notwithstanding, Fisher's exact test showed that medical students $(18.2 \%, \mathrm{~N}=2)$ perceived this activity to be helpful compared to pharmacy $(10 \%, N=2)$, or nursing $(2.3 \%, n=1)$. Also, none of the pharmacy students chose "hypnosis", while none of the medical students chose "a special diet or avoiding certain foods" as helpful activities for schizophrenia.
Knowledge of likely prognosis

Figures 2 and 3 describe health professional students' responses to questions about the likely prognosis if the person indicated in the depression or schizophrenia vignette received or did not receive professional help. For both questions, there were no significant differences between the three health professional student groups. For the question on when professional help is received, majority of respondents (Depression $\mathrm{N}=48$, Schizophrenia $\mathrm{N}=43$ ) chose the option "full recovery, but problems would probably re-occur" for both depression and schizophrenia from among the various response options. When examining the response option "full recovery with no further problems when professional help is received (Depression $\mathrm{N}=14$, schizophrenia $\mathrm{N}=3$ ), majority of the respondents who chose this option for the depression vignette were nursing students $(71.4, \mathrm{~N}=10)$ compared to medicine $(14.3 \%, \mathrm{~N}=2)$ or pharmacy students $(14.3 \%, \mathrm{~N}=2)$. However, this response option was not chosen by majority of students from all three programs for schizophrenia.

Figure 3 shows that there was less variability among the choice of responses regarding likely prognosis when no professional help was received for both depression $(\mathrm{N}=77)$ and schizophrenia $(\mathrm{N}=74)$. Majority of the respondents (depression $\mathrm{N}=45$, schizophrenia $\mathrm{N}=63$ ) chose the option "get worse". For schizophrenia, three response choices (partial recovery $(2.7 \%, \mathrm{~N}=2)$, no improvement $(12.2 \%, \mathrm{~N}=9)$, and get worse $(85.1 \% \mathrm{~N}=63)$, were primarily chosen by respondents in all three program types.

\section{Discussion}

We found no significant differences by health professional program type in students' ability to correctly identify the disease condition (depression and schizophrenia) in the vignettes. Majority of the students correctly determined that medical providers such as psychiatrists and psychologists would be the most helpful providers for depression and schizophrenia. However, though non-significant, there was a difference based on the disease state with respect to the next level of providers (after psychiatrists and psychologists) that would be most helpful. After clinical medical providers, respondents indicated that help from friends and family might be helpful for depression, however, for schizophrenia, they preferred other healthcare professionals (social workers, telephone counseling, etc.). Additionally, nursing and pharmacy students indicated the use of antidepressants as being useful for schizophrenia, however only a small minority of medical students chose antidepressants. A greater percent of nursing students felt that full recovery could be achieved if professional help was obtained for depression. However, there was broad agreement among students from all three types of programs that problems would reoccur even with full recovery when professional help was present for depression. Similarly, respondents clearly indicated that for schizophrenia, lack of professional help was more likely to either lead to no improvement or worsening of symptoms. Overall, all three 
health professional students had similar perceptions of providers that would be most helpful. Our results are similar to that reported in the literature. ${ }^{19,21,22,23}$ While studies in the literature used medical providers, or focused on just one type of provider, this is the first study conducted in the US to compare three different health profession students with respect to their mental health literacy.

In our study even though the top three choices of providers for depression and schizophrenia were similar among the three professions, closer examination of the top choices within each profession indicated subtle differences. The first choice of helpful individuals for depression for nursing students were counselors, followed by psychiatrists and psychologists. Medical students clearly mentioned medical providers such as family physicians or psychiatrists as their first choice, while pharmacy students mentioned counselor and psychiatrist as their first choice. Previous studies in the literature have reported that Australian medical doctors chose their profession and treatments higher than others as being helpful. ${ }^{21}$ Our study results seem to corroborate the same with respect to medical students. This also brings to attention the lack of understanding among the three professions about the role of other psychosocial providers such as social workers, peer specialists etc., who can offer valuable supportive roles when caring for patients with depression and schizophrenia.

All three health professional students correctly chose antidepressants for treating depression and antipsychotics for treating schizophrenia as the most frequent choice of medication that was helpful for depression and schizophrenia, respectively. However, some nursing students also chose additional medication categories such as antipsychotics and vitamins for treating depression. There was a wider distribution of medication choices among pharmacy and nursing students for helpfulness of medications to treat schizophrenia compared to medical students. In addition to antipsychotics, which was their most frequent choice, pharmacy and nursing students also chose antidepressants, tranquilizers, and sedatives/hypnotics as being helpful to treat schizophrenia. O'Reilly examined pharmacists' beliefs about treatments and outcomes using the same survey in Australia and reported similar results. ${ }^{22}$ Statistically significant differences between students in the three health professions on the helpfulness of antidepressants for schizophrenia may be explained by the differences in curricular training on mental health. At the university where this study was conducted, a required eight week psychiatric mental health course is taught only in the final year for nursing students, while for medical students mental health is taught in every year of the curriculum, and pharmacy students have a third year required integrated course containing mental health and other topics related to psychiatry and neurology. Thus, the education about mental health is not reinforced as often for pharmacy and nursing students which may explain significant differences in choice of medications. All three types of health professional students are trained as general practitioners and hence there might not be the desired emphasis on mental health that is needed to meet the growing needs of the patients they serve. McKee et al. have reported that final year pharmacy students had an "average level of knowledge" about psychotherapeutic agents. ${ }^{30}$ Given the extent of the problem of mental health, more and continuously reinforced training on mental health throughout the didactic curriculum is necessary for at least those who plan to become community-based providers such as pharmacists and physicians. Support for the call for additional mental health training is also perceived as an important need among current practitioners. To address this need, a large community pharmacy chain recently initiated a four hour interactive online course with certification in mental health first aid. ${ }^{31}$ The course called Mental Health First Aid (MHFA) first developed in Australia, aims to train pharmacists to identify warning signs and offer support to someone experiencing a mental health disorder or mental health crisis until professional help can be obtained or the crisis resolves. ${ }^{32}$ MHFA training has been studied in medical, and nursing students in Australia, ${ }^{33,34}$ however, it is only now gaining exposure in the United States.

For pharmacy students, activities chosen as being helpful for depression in our study were similar to that reported with pharmacists in the literature. ${ }^{22}$ Similarly, our findings were comparable to the only study that surveyed nursing and medical students in aggregate in Singapore. ${ }^{23}$ The high emphasis on physical activity for depression and less so for schizophrenia by all three professions suggests that students understood the differences in etiology of depression and schizophrenia and the activities that would be most beneficial for each. We found a significant difference between the three professions for the activity "having an occasional drink to relax" for schizophrenia. It is unclear why there were significant differences between professions for this item. This is not consistent with literature and should be interpreted with caution due to the small sample sizes in the three groups. Another statement "cutting alcohol out together" was viewed favorably by all professions for both disease states.

This study has several limitations. A significant limitation is the low generalizability of the study results due to focus on a single university. Another limitation is the low response rates for pharmacy and medicine due to online administration necessitated due to final year medical and pharmacy students being off campus on clinical rotations. We were unable to offer incentives for survey completion which may have contributed to low response rates. However, we attempted to mitigate this by having multiple waves of online administrations. 


\section{Conclusion}

This study shows that majority of students in each discipline were correctly able to identify patients with depression or schizophrenia and had similar levels of mental health literacy. The pattern of responses suggested that pharmacy and nursing students in particular were clearer about helpfulness of various interventions for depression, than for schizophrenia. Majority of the students from all three professions perceived that even with professional help, problems would reoccur. Courses such as Mental Health First Aid (MHFA) training could serve as a solution to enhance the skills of these first line providers.

\section{Conflicts of interest: None}

Treatment of Human subjects: IRB exemption granted.

\section{References}

1. Mental health by the numbers : https://www.nami.org/Learn-More/Mental-HealthBy-the-Numbers. Accessed on 5/3/19.

2. Jorm, A. F. "Mental Health Literacy: Public Knowledge and Beliefs about Mental Disorders." The British Journal of Psychiatry. 2000 Nov; 177(5): 396401.

3. 3)Phokeo V, Sproule B, Raman-Wilms L. Community pharmacists' attitudes toward and professional interactions with users of psychiatric medications. Psychiatric Serv 2004; 55(12): 1434-6

4. Rickles NM, Dube GL, McCarter A, Olshan JS. Relationship between attitudes towards mental illness and provision of pharmacy services. J Am Pharm Assoc 2010; 50: 704-713.

5. Bell JS, Aaltonen E, Bronsteil E, Desplenter FA Foulon V, Vitola A, Muceniece R, Gharat MS, Volmer $D$, Airaksinen MS, Chen TF. Attitudes of pharmacy students toward people with mental disorders, a six country study. Pharm World Sci 2008; 30:595-599

6. Volmer D, Maesalu M, Bell JS. Pharmacy students' attitudes toward and professional interactions with people with mental disorders. Int J Soc Psychiatry. 2008 54(5): 402-13.

7. O'Reilly C, Bell JS, Chen TF. Mental health consumers and caregivers as instructors for health professional students: a qualitative study. Soc Psychiatr Epidemiol 2012; 47: 607-613.

8. O'Reilly CL, Bell JS, Chen TF. Consumer-led mental health education for pharmacy students. Am J Pharm Educ 2010; 74(9); 167.

9. Bamgbade BA, Ford $\mathrm{KH}$, Barner JC. Impact of a mental illness stigma awareness intervention on pharmacy student attitudes and knowledge. Am J Pharm Educ 2016; 80(5): 80.
10. Dipaula BA, Qian J, Mehdizadegan N, Simoni-Wastila L. An elective psychiatric course to reduce pharmacy students' social distance toward people with severe mental illness. Am J Pharm Educ. 2011; 75(4): 72.

11. Bell JS, Johns R, Chen TF. Pharmacy students' and graduates' attitudes towards people with schizophrenia and severe depression. Am J Pharm Educ 2006; 70(4): 77.

12. Cates ME, Neace AL, Woolley TW. Pharmacy students' attitudes toward mental illness at the beginning and end of the professional curriculum. Currents in Pharmacy Teaching and Learning2012 4(2): 132-136.

13. Buhler AV, Karimi RM. Peer-level patient presenters decrease pharmacy students' social distance fom patients with schizophrenia and clinical depression. Am J Pharm Educ 2008; 72(5): 106

14. Patten SB, Remillard A, Phillips L, Modgill G, Szeto $\mathrm{ACH}$, Kassam A, Gardner D. Effectiveness of contactbased education for reducing mental illness-related stigma in pharmacy students. BMC Educ 2012; 12: 120.

15. Muzyk AJ, Lentz K, Green C, Fuller S, May DB, Roukema L. Emphasizing bloom's affective domain to reduce pharmacy students' stigmatizing attitudes. Am J Pharm Educ 2017; 81(2): 35.

16. "Mental health literacy", a survey of the public's ability to recognize mental disorders and their beliefs about the effectiveness of treatment. Med J Aust 1997; 166(4): 182-6.

17. Reavley NJ, Jorm AF. Recognition of mental disorders and beliefs about treatment and outcomes: findings from an Australian national survey of mental health literacy and stigma. Aust $\mathrm{N}$ Z J Psychiatry. 2011 45(11):947-56.

18. Reavley NJ and Jorm AF. Young people's recognition of mental disorders and beleifs about treatment and outcome; findings from an Australian national survey. Aust N Z J Psychiatry2011; 45:890-898.

19. Jorm AF, Korten AE, Jacomb PA, Rodgers $B$, Pollitt $P$. Beliefs about the helpfulness of interventions for mental disorders: a comparison of general practitioners, psychiatrists, and clinical psychologists. Aust N Z J Psychiatry. 1997; 31: 844851.

20. Jorm AF, Korten AE, Jacomb PA, Rodgers B, Pollitt $P$, Christensen $\mathrm{H}$, Henderson $\mathrm{S}$. Helpfulness of interventions for mental disorders: beliefs of health professionals compared with the general public. $\mathrm{Br}$ J Psychiatry. 1997 171: 233-7.

21. Morgan, AJ, Jorm AF, and Reavley NJ. Beliefs of Australian Health Professionals about the Helpfulness of Interventions for Mental Disorders: Differences between Professions and Change over Time. Aust N Z J Psychiatry. 2013; 47(9):840-848. 
22. O'Reilly CL, Simon Bell J, and Chen TF. Pharmacists' Beliefs about Treatments and Outcomes of Mental Disorders: A Mental Health Literacy Survey. Aust N Z J Psychiatry 2010; 44(12):1089-1096.

23. Picco L, Seow E, Chua BY, Mahendran R, Verma S, Xie $\mathrm{H}$, wang J, Chong SA, Subramaniam M. Help-seeking beliefs for mental disorders among medical and nursing students. Early Interv Psychiatry 2019 13(4): 823-831.

24. Liu W, Li YM, Peng Y. Mental health literacy: A cross-cultural study of American and Chinese bachelor of nursing students. J Psychiatr Ment Health Nurs. 2018; 25: 96-107.

25. Sayarifard A, Ghadirian L, Mohit A, Mehrdad E, badpa M, Rajabi F. Assessing mental health literacy: What medical sciences students' know about depression. Med J Islam Repub Iran. 2015; 29: 161.

26. Hanna LA, Bakir M, Hall M. UK Pharmacy students' opinions on mental health conditions. Am J Pharm Educ 2018; 82(7): 6560.

27. Cates ME, Monk-Tutor MR, Drummond SO. Mental health and psychiatric pharmacy instruction in US colleges and schools of pharmacy. Am J Pharm Educ 2007; 71(1): 04.

28. Gable KN, Muhlstadt KL, Celio MA. A mental health elective to improve pharmacy students' perspectives on mental illness. Am J Pharm Educ 2011; 75(2): 34.
29. Reavley NJ, Morgan AJ, Jorm AF. Development of scales to assess mental health literacy relating to recognition of and interventions for depression, anxiety disorders, and schizophrenia/psychosis. Aust N Z J Psychiatry. 2014; 48(1): 61-9.

30. McKee BD, Larose-Pierre M, Rappa LR. A survey of community pharmacists and final year student pharmacists and their perception of psychotherapeutic agents. J of Pharmacy Practice 2015; 28(2): 166-174.

31. 31) Johnson SR. Walgreens to train for pharmacy staff in Mental Health First Aid. Modern Healthcare. 5/1/2019. Accessed on 5/8/19

(https://www.modernhealthcare.com/safetyquality/walgreens-train-pharmacy-staff-mentalhealth-first-aid).

32. 32) Jorm AF. Mental health Literacy: Empowering the community to take action for better mental health. Am Psychol 2012; 67(3): 231-43.

33. 33) O'Reilly CL, Bell JS, Kelly PJ, Chen TF. Impact of mental health first aid training on pharmacy students' knowledge, attitudes, and self-reported behavior: a controlled trial. Aust N Z J Psychiatry. 2011; 45(7):549-57.

34. 34) Bond KS, Jorm AF, Kitchener BA, Reavley NJ. Mental health first aid training for Australian medical and nursing students: an evaluation study. BMC Psychol 2015; 3(1): 11. 
Table 1

\section{Depression Vignette}

John/Jane is 30 years old. He/she has been feeling unusually sad and miserable for the last few weeks. Even though he/she is tired all the time, he/she has trouble sleeping nearly every night. John/Jane doesn't feel like eating and has lost weight. He/she can't keep his/her mind on his/her work and puts off making decisions. Even day-to-day tasks seem too much for him/her. This has come to the attention of his boss, who is concerned about John's lowered productivity.

\section{Schizophrenia vignette}

John/Jane is 24 and lives at home with his/her parents. He/she has had a few temporary jobs since finishing school but is now unemployed. Over the last six months he/she has stopped seeing his/her friends and has begun locking himself/herself in his/her bedroom and refusing to eat with the family or to have a bath. His/her parents also hear him/her walking about his/her bedroom at night while they are in bed. Even though they know that he/she is alone, they have heard him/her shouting and arguing as if someone else is there. When they try to encourage him/her to do more things, he/she whispers that he/she won't leave home because he/she is being spied upon by the neighbor. They realize he/she is not taking drugs because he/she never sees anyone or goes anywhere. 
Table 2: Demographics of the sample

\begin{tabular}{|c|c|c|c|c|c|}
\hline Category & $\begin{array}{l}\text { Total }(\mathrm{N}=151)^{*} \\
\text { Percent }(\mathrm{N})\end{array}$ & $\begin{array}{l}\text { Nursing }(\mathrm{N}=86) \\
\text { Percent }(\mathrm{N})\end{array}$ & $\begin{array}{l}\text { Medicine (N=20) } \\
\text { Percent (N) }\end{array}$ & $\begin{array}{l}\text { Pharmacy }(\mathrm{N}=45) \\
\text { Percent }(\mathrm{N})\end{array}$ & $P$ value \\
\hline $\begin{array}{l}\text { Age } \\
21-25 \text { years } \\
26-30 \text { years } \\
31-35 \text { years } \\
41-50 \text { years }\end{array}$ & $\begin{array}{l}78(118) \\
15(23) \\
4.6(7) \\
2(3)\end{array}$ & $\begin{array}{l}79(92) \\
3.5(3) \\
2.3(2) \\
2.0(2)\end{array}$ & $\begin{array}{l}25(5) \\
65(13) \\
10(2) \\
0\end{array}$ & $\begin{array}{l}75.6(34) \\
15.6(7) \\
6.7(3) \\
2.2(1)\end{array}$ & $P<0.0001$ \\
\hline $\begin{array}{l}\text { Gender } \\
\text { Male } \\
\text { Female }\end{array}$ & $\begin{array}{l}25.2(38) \\
75.0(113)\end{array}$ & $\begin{array}{l}15.1(13) \\
85(73)\end{array}$ & $\begin{array}{l}30(6) \\
70(14)\end{array}$ & $\begin{array}{l}42(19) \\
58(26)\end{array}$ & 0.003 \\
\hline $\begin{array}{l}\text { Ethnicity } \\
\text { Caucasian White } \\
\text { African American } \\
\text { Hispanic/Latin American } \\
\text { Asian } \\
\text { Natïve Hawaiian/Pacific } \\
\text { islander } \\
\text { Mixed }\end{array}$ & $\begin{array}{l}84.6(126) \\
7.4(11) \\
2.0(3) \\
1.3(2) \\
2.7(4) \\
2.0(3)\end{array}$ & $\begin{array}{l}84.5(74) \\
8.3(7) \\
3.6(3) \\
0 \\
1.2(1) \\
2.4(2)\end{array}$ & $\begin{array}{l}80(16) \\
5.0(1) \\
0 \\
5.0(1) \\
5.0(1) \\
\\
5.0(1)\end{array}$ & $\begin{array}{l}86.7(39) \\
6.7(3) \\
0 \\
2.2(1) \\
4.4(2) \\
\\
0\end{array}$ & 0.35 \\
\hline $\begin{array}{l}\text { Currently or in the past } \\
\text { year interacted with } \\
\text { people diagnosed with } \\
\text { any mental health } \\
\text { disorders on a regular } \\
\text { basis. } \\
\text { Yes } \\
\text { No }\end{array}$ & $\begin{array}{l}90(137) \\
10(15)\end{array}$ & $\begin{array}{l}96.5(83) \\
3.5(3)\end{array}$ & $\begin{array}{l}95(19) \\
5.0(1)\end{array}$ & $\begin{array}{l}76(35) \\
24(11)\end{array}$ & 0.001 \\
\hline $\begin{array}{l}\text { Coursework completed } \\
\text {-A required course } \\
\text { dedicated to mental } \\
\text { health and/or psych } \\
\text { disorders. } \\
\text {-Coursework included } \\
\text { topics on mental health } \\
\text { but also non-mental } \\
\text { health topics. } \\
\text { No coursework on mental } \\
\text { health } \\
\text {-Experiential training on } \\
\text { mental health only } \\
\text {-Took a mental health } \\
\text { elective course (either } \\
\text { didactic or experiential) } \\
\text {-Took a complete course } \\
\text { on addiction only } \\
\text {-Checked multiple boxes }\end{array}$ & $\begin{array}{l}3.3(5) \\
0 \\
1.3(2) \\
5.3(8) \\
2.0(3) \\
49(74)\end{array}$ & $\begin{array}{l}24.7(21) \\
0 \\
0 \\
0 \\
0 \\
0 \\
74.4(64)\end{array}$ & $\begin{array}{l}15(3) \\
0 \\
0 \\
0\end{array}$ & $\begin{array}{l}56.5(26) \\
4.3(2) \\
0 \\
4.3(2) \\
17.4(8) \\
6.5(3) \\
11(5)\end{array}$ & $<0.001$ \\
\hline
\end{tabular}


Figure 1: Percent correctly identifying each vignette*

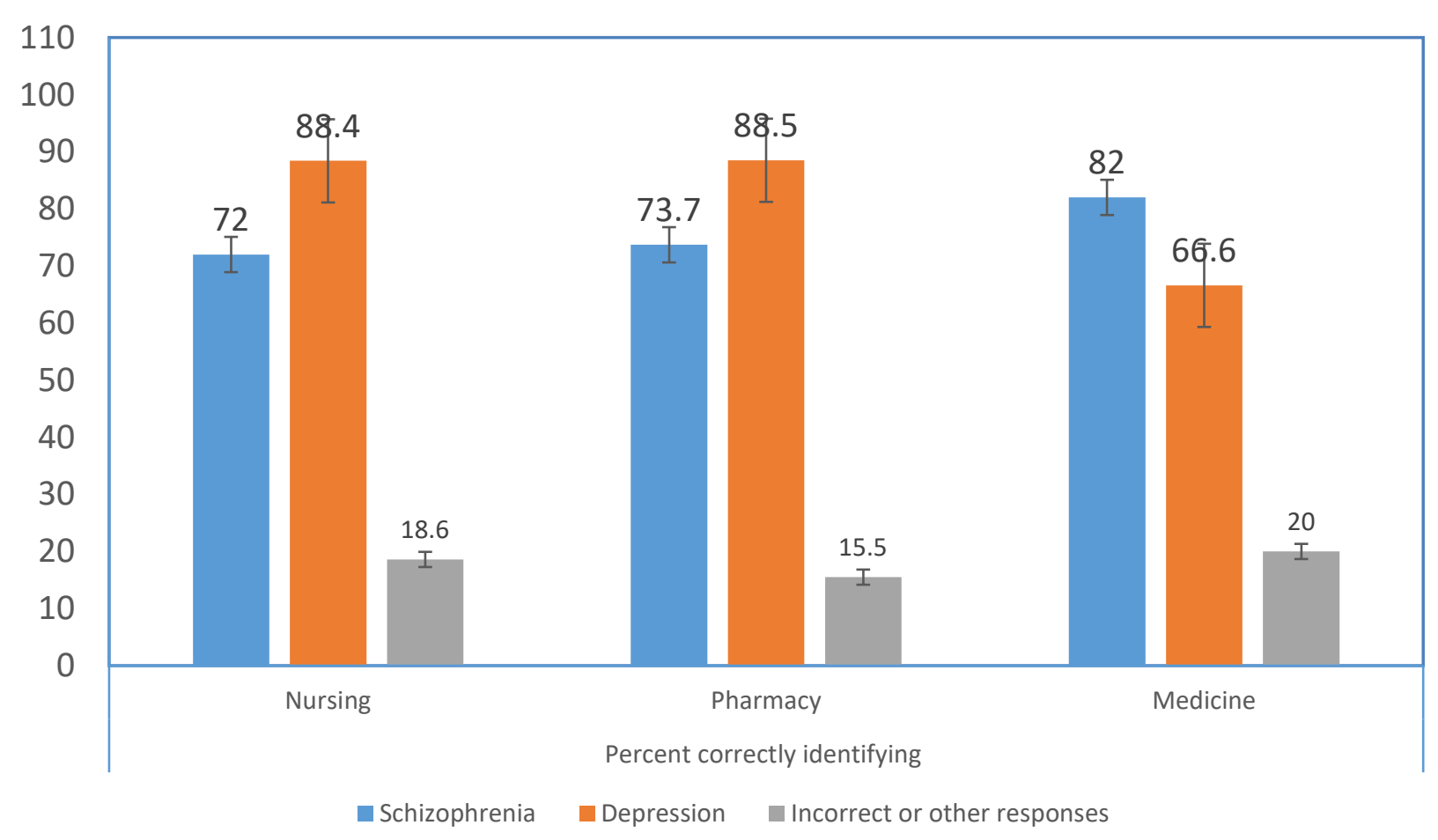

* Out of a total of 161 responses, $\mathrm{N}=10$ missing. There were 86 Nursing students, 45 pharmacy students, and 20 Medical students.

No significant differences by program type 
Table 3: Health professional student perceptions of helpfulness of individuals, medications, and activities as interventions

\begin{tabular}{|c|c|c|c|c|c|c|c|c|}
\hline & \multicolumn{4}{|c|}{ Depression $(\mathrm{N}=82)$} & \multicolumn{4}{|c|}{ Schizophrenia $(\mathrm{N}=78)$} \\
\hline Helpfulness of interventions & $\begin{array}{l}\text { Nursing* } \\
(\mathrm{N}=43) \\
\mathrm{N}(\%)\end{array}$ & $\begin{array}{l}\text { Medicine* } \\
(\mathrm{N}=9) \\
\mathrm{N}(\%)\end{array}$ & $\begin{array}{l}\text { Pharmacy* } \\
(\mathrm{N}=26) \\
\mathrm{N}(\%)\end{array}$ & $P$ value & $\begin{array}{l}\text { Nursing* } \\
(\mathrm{N}=43) \\
\mathrm{N}(\%)\end{array}$ & $\begin{array}{l}\text { Medicine* } \\
(\mathrm{N}=11) \\
\mathrm{N}(\%)\end{array}$ & $\begin{array}{l}\text { Pharmacy* } \\
(\mathrm{N}=20) \\
\mathrm{N}(\%)\end{array}$ & $P$ value \\
\hline \multicolumn{9}{|l|}{ People who could help: } \\
\hline A family physician or doctor & $35(83.3)$ & $9(100)$ & $19(73.0)$ & 0.23 & $28(67.0)$ & $8(73.0)$ & $9(45.0)$ & 0.4 \\
\hline A pharmacist & $14(33.3)$ & $3(33.3)$ & $12(46.2)$ & 0.55 & $15(37.5)$ & $2(18.2)$ & $7(35.0)$ & 0.55 \\
\hline A counselor & $41(97.6)$ & $8(89.0)$ & $23(88.5)$ & 0.24 & $32(78.0)$ & $10(91.0)$ & $15(75.0)$ & 0.95 \\
\hline A social worker & $27(64.3)$ & $7(78.0)$ & $16(61.5)$ & 0.90 & $25(62.5)$ & $9(82.0)$ & $15(75.0)$ & 0.67 \\
\hline $\begin{array}{l}\text { Telephone counseling service } \\
\text { (e.g., Lifeline) }\end{array}$ & $32(76.2)$ & $5(56)$ & $17(65.4)$ & 0.30 & $21(50.0)$ & $7(63.6)$ & $12(60.0)$ & 0.63 \\
\hline A psychiatrist & $38(90.5)$ & $9(100)$ & $23(88.5)$ & 0.51 & $41(97.6)$ & $9(82.0)$ & $19(95.0)$ & 0.05 \\
\hline A psychologist & $36(86.0)$ & $8(89.0)$ & $22(85)$ & 0.69 & $38(90.5)$ & $9(82.0)$ & $17(85)$ & 0.13 \\
\hline Help from his close family & $33(79.0)$ & $6(67.0)$ & $15(58.0)$ & 0.18 & $18(43.0)$ & $5(45.5)$ & $12(60.0)$ & 0.82 \\
\hline Help from close friends & $33(79.0)$ & $5(62.5)$ & $15(60.0)$ & 0.20 & $14(33.3)$ & $4(40.0)$ & $12(60.0)$ & 0.27 \\
\hline A naturopath or herbalist & $6(14.3)$ & $3(33.3)$ & $3(11.5)$ & 0.01 & $1(2.4)$ & $2(18.2)$ & $1(5.0)$ & 0.59 \\
\hline The clergy, a minister, or priest & $24(57.1)$ & $3(33.3)$ & $7(27.0)$ & 0.02 & $12(28.6)$ & $4(36.4)$ & $7(35.0)$ & 0.93 \\
\hline $\begin{array}{l}\text { John tries to deal with problems } \\
\text { on his own. }\end{array}$ & $1(2.4)$ & $2(22.2)$ & $2(7.7)$ & 0.31 & $0(0.0)$ & $0(0.0)$ & $0(0.0)$ & 0.13 \\
\hline
\end{tabular}

\section{Medications that can help}

\begin{tabular}{|c|c|c|c|c|c|c|c|c|}
\hline $\begin{array}{l}\text { Vitamins and minerals, tonics, or } \\
\text { herbal medicines }\end{array}$ & $13(30.2)$ & 0 & 0 & 0.012 & $5(11.6)$ & 0 & $1(5.0)$ & 0.70 \\
\hline Analgesics & $1(2.4)$ & 0 & 0 & 0.39 & $3(7.1)$ & 0 & 0 & 0.75 \\
\hline Antidepressants & $37(86.0)$ & $7(78.0)$ & $21(81.0)$ & 0.74 & $31(72.1)$ & $2(18.2)$ & $11(55.0)$ & 0.009 \\
\hline Antibiotics & 0 & 0 & 0 & 0.73 & 0 & 0 & 0 & 0.49 \\
\hline Sedatives/hypnotics & $5(12.0)$ & 0 & $1(3.8)$ & 0.29 & $12(28.0)$ & 0 & $2(10.0)$ & 0.16 \\
\hline Antipsychotics & $11(26.0)$ & 0 & $2(7.7)$ & 0.35 & $39(91.0)$ & $10(91.0)$ & $15(75.0)$ & 0.21 \\
\hline Tranquilizers such as Valium & 5 (11.6) & 0 & 0 & 0.02 & $10(23.3)$ & $1(9.1)$ & $3(15.0)$ & 0.60 \\
\hline
\end{tabular}

\section{Performing Activities}

\begin{tabular}{|c|c|c|c|c|c|c|c|c|}
\hline Becoming more physically active & $38(88.4)$ & $9(100.0)$ & $24(92.3)$ & 1.00 & $28(65.1)$ & $8(73.0)$ & $15(75.0)$ & 0.37 \\
\hline $\begin{array}{l}\text { Reading about people with } \\
\text { similar problems and how they } \\
\text { have dealt with them }\end{array}$ & $36(84.0)$ & $8(89.0)$ & $22(85.0)$ & 1.0 & $32(74.4)$ & $10(91.0)$ & $16(80.0)$ & 0.94 \\
\hline Getting out and about more & $36(84.0)$ & $7(78.0)$ & $15(58.0)$ & 0.19 & $17(39.5)$ & $6(54.5)$ & $9(45.0)$ & 0.06 \\
\hline $\begin{array}{l}\text { Courses on relaxation, stress } \\
\text { management, meditation, or } \\
\text { yoga }\end{array}$ & $41(95.3)$ & $7(78.0)$ & $22(85.0)$ & 0.04 & $31(72.1)$ & $6(54.5)$ & $16(80.0)$ & 0.38 \\
\hline Cutting out alcohol altogether & $29(67.4)$ & $5(55.6)$ & $18(69.2)$ & 0.38 & $36(84.0)$ & $9(82.0)$ & $11(55.0)$ & 0.13 \\
\hline
\end{tabular}


Original Research

PHARMACY PRACTICE

\begin{tabular}{|c|c|c|c|c|c|c|c|c|}
\hline Psychotherapy & $28(65.1)$ & $6(66.7)$ & $20(77.0)$ & 0.66 & $40(95.2)$ & $10(91.0)$ & $17(85.0)$ & 0.34 \\
\hline Cognitive behavior therapy & $28(65.1)$ & $9(100.0)$ & $24(92.3)$ & 0.16 & $37(86.0)$ & $8(72.7)$ & $19(95.0)$ & 0.21 \\
\hline Hypnosis & $8(18.6)$ & 0 & 0 & 0.04 & $12(28.0)$ & $1(10.0)$ & 0 & 0.21 \\
\hline $\begin{array}{l}\text { Admission to psychiatric ward of } \\
\text { a hospital }\end{array}$ & $5(11.6)$ & 0 & 0 & 0.19 & $21(49.0)$ & $10(91.0)$ & $6(30.0)$ & 0.02 \\
\hline Electroconvulsive therapy & $4(9.3)$ & 0 & $3(11.5)$ & 0.67 & $11(25.6)$ & $4(36.4)$ & $6(30.0)$ & 0.42 \\
\hline $\begin{array}{l}\text { Having an occasional alcoholic } \\
\text { drink to relax }\end{array}$ & $1(2.3)$ & $4(44.4)$ & $1(3.8)$ & 0.52 & $1(2.3)$ & $2(18.2)$ & $2(10.0)$ & 0.007 \\
\hline $\begin{array}{l}\text { A special diet or avoiding certain } \\
\text { foods }\end{array}$ & $20(46.5)$ & $1(11.1)$ & $7(27.0)$ & 0.01 & $12(28.0)$ & 0 & $1(5.3)$ & 0.012 \\
\hline $\begin{array}{l}\text { Consulting a website that gives } \\
\text { information about his/her } \\
\text { problem }\end{array}$ & $14(32.6)$ & $3(33.3)$ & 9 (34.6) & 0.66 & $10(23.8)$ & $3(27.3)$ & $5(25.0)$ & 0.89 \\
\hline $\begin{array}{l}\text { Consulting an expert using email } \\
\text { or the web about his/her } \\
\text { problem }\end{array}$ & $21(49.0)$ & $3(33.3)$ & $16(61.5)$ & 0.31 & $15(35.0)$ & $3(27.3)$ & $6(30.0)$ & 0.67 \\
\hline $\begin{array}{l}\text { Consulting a book that gives } \\
\text { information about his/her } \\
\text { health problem }\end{array}$ & $29(67.4)$ & 5 (55.6) & $12(46.2)$ & 0.17 & $21(49.0)$ & $4(36.4)$ & $9(45.0)$ & 0.79 \\
\hline $\begin{array}{l}\text { Receiving information about } \\
\text { health problem from a health } \\
\text { educator }\end{array}$ & $38(88.4)$ & $7(78.0)$ & $20(77.0)$ & 0.28 & $36(84.0)$ & $10(91.0)$ & $16(80.0)$ & 0.76 \\
\hline
\end{tabular}

Numbers do not round to totals due to missing values. P values based on Fisher's exact test. 
Figure 2: Comparison of health professional program responses regarding likely prognosis if appropriate professional help was obtained (Depression $n=78$, Schizophrenia $N=74)(p>0.05)$

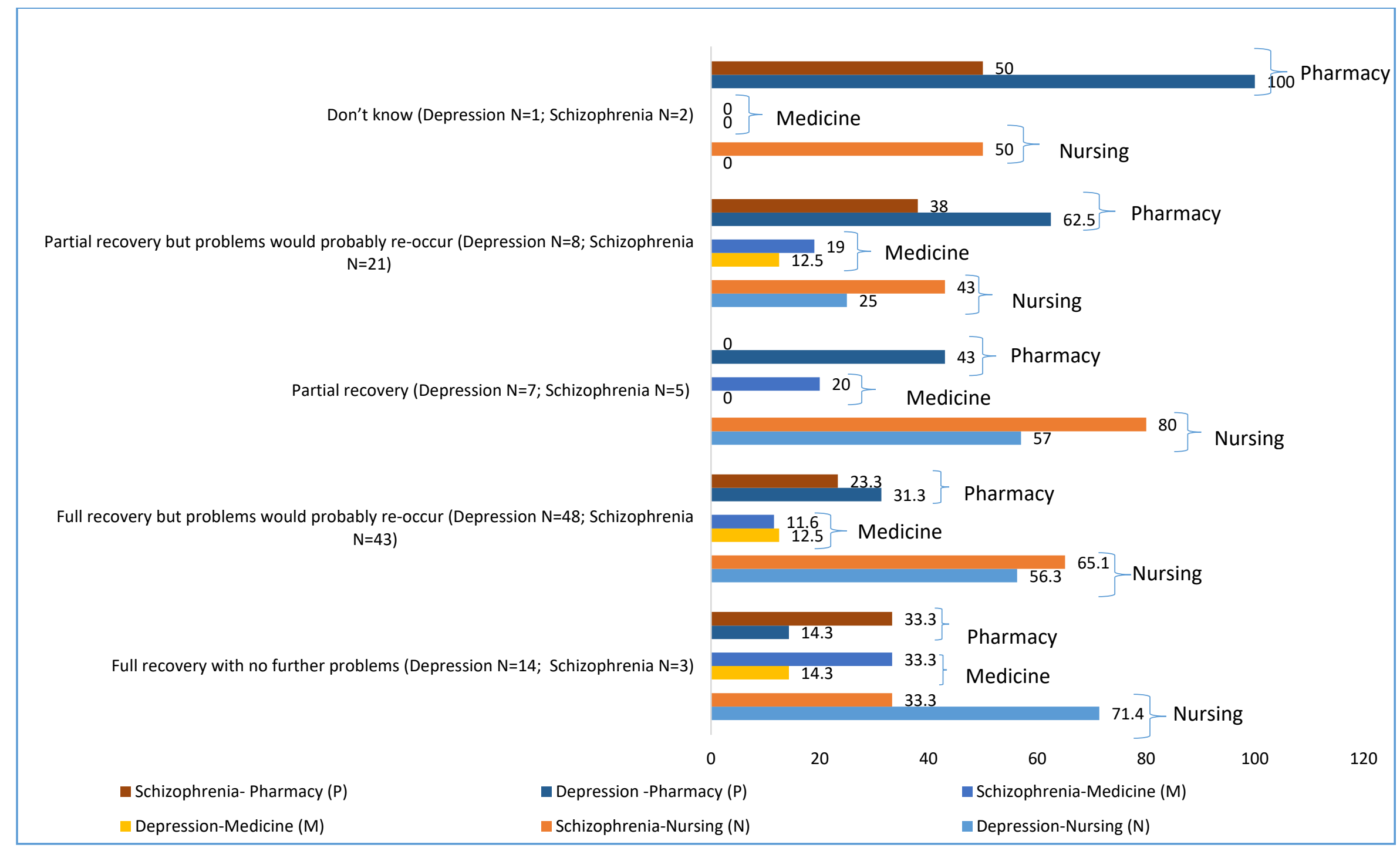


Figure 3: Comparison of health professional program responses regarding likely prognosis if appropriate professional help was NOT obtained (Depression $\mathrm{N}=\mathbf{7 7}$, Schizophrenia $\mathrm{N}=74)(\mathrm{p}>0.05)$

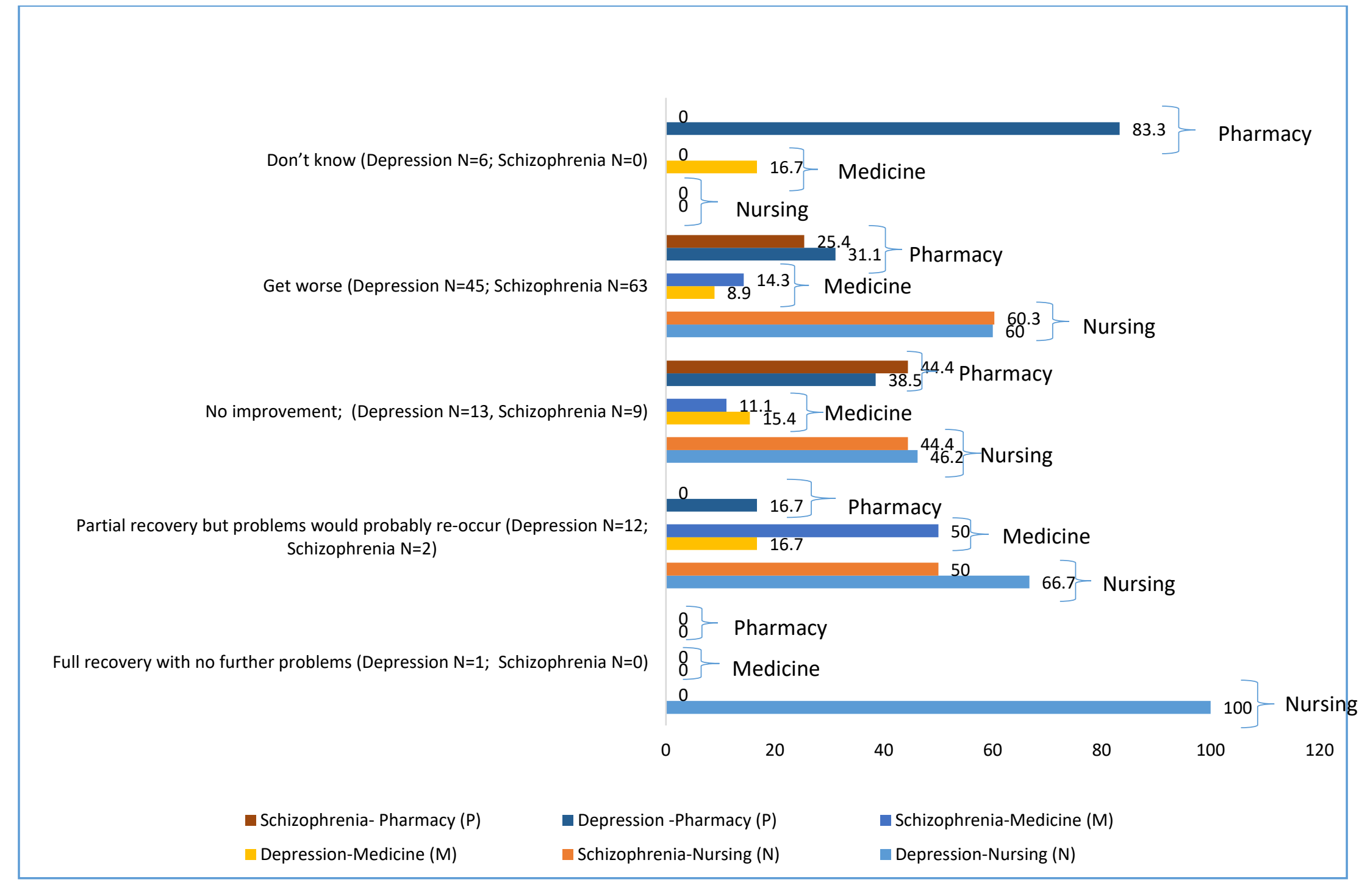

